\begin{tabular}{|l|l|}
\hline $\begin{array}{l}\text { La historia de Potosí de Arzans y el ciclo dramático altoperuano de la muerte de } \\
\text { Atahualpa }\end{array}$ & Titulo \\
\hline Ajens, Andrés - Autor/a; & Autor(es) \\
\hline $\begin{array}{l}\text { De Raíz Diversa. Revista Especializada en Estudios Latinoamericanos (Vol. 3 no. 5 } \\
\text { ene-jun 2016) }\end{array}$ & En: \\
\hline México D.F. & Lugar \\
\hline $\begin{array}{l}\text { Programa de Posgrado en Estudios Latinoamericanos, Universidad Nacional } \\
\text { Autónoma de México }\end{array}$ & Editorial/Editor \\
\hline 2016 & Fecha \\
\hline $\begin{array}{l}\text { Sobrino, Juan; Quechuas; Arzáns de Orsúa y Vela, Bartolomé; Poética; Historia; } \\
\text { Bolivia; América Latina; Potosí; }\end{array}$ & Colección \\
\hline Artículo & Temas \\
\hline $\begin{array}{l}\text { "http///biblioteca.clacso.edu.ar/Mexico/ppel-unam/20160629042806/1_La_Historia_de_Potosi_de_Arzans_y_el_ciclo_dramatico_altoperu } \\
\text { ano_de_la_muerte_de_Atahualpa._Andres_Ajens.pdf" }\end{array}$ & URL \\
\hline $\begin{array}{l}\text { Reconocimiento-No Comercial-Sin Derivadas CC BY-NC-ND } \\
\text { http://creativecommons.org/licenses/by-nc-nd/2.0/deed.es }\end{array}$ & Licencia \\
\hline
\end{tabular}

Segui buscando en la Red de Bibliotecas Virtuales de CLACSO http://biblioteca.clacso.edu.ar

Consejo Latinoamericano de Ciencias Sociales (CLACSO)

Conselho Latino-americano de Ciências Sociais (CLACSO)

Latin American Council of Social Sciences (CLACSO)

www.clacso.edu.ar

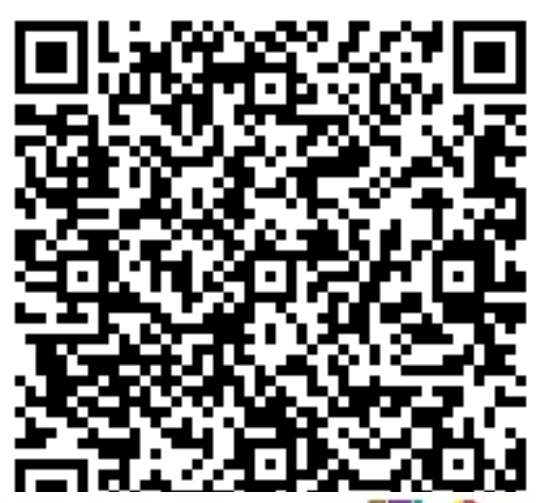

Consejo Latinoamericano de Ciencias Sociales

Conselho Latino-americano de Ciências Sociais 


\section{La Historia de Potosí de Arzans y el ciclo dramático altoperuano de la muerte de Atahualpa*}

ANDRÉs AJENS**

Resumen. A partir de un análisis de los planteamientos de poética expuestos por Bartolomé de Arzans de Orsúa y Vela en pasajes de su Historia de la Villa Imperial de Potosí (s. XVIII), así como de la figura del "poeta historiador" Juan Sobrino - que opera como fuente temprana para la misma-, y de otros datos de orden lingüístico, retórico e histórico, reconsideramos la verosimilitud del pasaje de la Historia relativo a la escenificación en 1555 en Potosí de una versión temprana, "en verso mixto del idioma castellano con el indiano", de las escenificaciones altoperuanas de la captura y muerte de Atahualpa. De paso, indicamos una fuente inédita (no identificada hasta ahora) de la Historia. La lectura se enlaza y discute en modos diversos con otras precedentes, entre las cuales: Lara (1957), Hanke y Mendoza (1965), Gisbert (1968, 1999), Burga (1988), Beyersdorff (1997) y Husson (1998, 2001).

Palabras Clave: Poética, Historia, Comedia, Quechua, Potosí.

Abstract. From an analysis of the poetic approaches presented by Bartolomé Arzans de Orsúa y Vela in parts of his History of the Imperial Villa of Potosí ( $18^{\text {th }}$ century) as well as the figure of the "poet historian" Juan Sobrino who was its early source, and other information from linguistics, rhetoric and history, the author reconsiders the plausibility of certain parts of the History considering the dramatization of 1555 in Potosí of the capture and death of Atahualpa in a verse in Spanish mixez $d$ with native languages. The author indicates an unprecedented (and so far unidentified) early source of the History. The reading is linked and discussed in various ways with other precedents such as Lara (1957), Hanke and Mendoza (1965), Gisbert (1968, 1999), Burga (1988), Beyersdorff (1997) and Husson (1998, 2001).

KEYwORDs: poetics, history, comedy, quechua, Potosí.

Recibido: 31 de agosto de 2015. ACeptado: 14 de octubre de 2015.

Escrito en el borde del proyecto "Huilliches y altoperuanos", con el apoyo del Consejo Nacional de la Cultura y las Artes, del Gobierno de Chile (FONDART de investigación ${ }^{\circ}$ 74452), 2015-2016.

** Poeta, traductor, catedrático chileno, <agonzalezwa@yahoo.com>. 
"Con este rico y excelente traje, manifestó el indio el que tuvieron sus antiguos reyes, que por ser muy semejantes sin quitar ni añadir cosa alguna, de la misma manera que aquí se ve, lo cuentan en sus historias el capitán Pedro Méndez y Bartolomé Dueñas, y no quise excusar de ponerlo por ver que tal pintura, si no es de mucha importancia, a lo menos no turba, ni altera la verdad y contexto de la Historia."

Arzans, Historia, $I^{a}, I V, 2$.

"Los historiadores que de mentiras se valen habian de ser quemados, como los que hacen moneda falsa"

Cervantes, El Quijote, II, 3.

$\mathrm{E}_{\mathrm{n}}$ más de un pasaje de la Historia de la Villa Imperial de Potosí (comienzos del s. XviII; [1965]), Bartolomé de Arzans de Orsúa y Vela explicita sus nociones de poética y las relaciones que la poesía mantendría con la historia - esto último, particularmente en referencia a la figura del "poeta historiador" Juan Sobrino, quien opera como una de las fuentes tempranas de la Historia.

Por ejemplo, en alusión a unas comedias interpretadas en Potosí en las fiestas de la jura del rey Luis Fernando I, en 1725, Arzans señala:

"Estas obras de poesía son una animada historia en que aquella [la poesía] o cría los sucesos o los viste, visibles sueños en que la razón se traspone con la armonía de los sentidos. La pintura forma en ella el lugar; la música, el agrado; la sentencia moral y el ritmo, la misma poesía y justamente la invención, observando aquellas tres difíciles unidades de acción, de lugar y de tiempo." (Arzans, 1965; subrayo).

Como "historia animada", entonces, gracias a la creación o a la vestidura (ampliación o engalanamiento) de la "verdad desnuda" de los sucesos, las "obras de poesía" no dejarían nunca de mantener un lazo constitutivo con la historia a secas, y viceversa. Ello no sólo a fines edificantes, de crítica social o de entretenimiento, que, junto a otros elementos, forman parte de su temple historiográfico (Hanke, 1965: LXxxiII-LXXxix). Es que para Arzans una historia no vivificada o "animada" por la poesía, una historia

1 La expresión viene en uno de los capítulos finales de la Historia, firmados por el hijo del autor, Diego (Arzans, 1965: 18). 
de la verdad absolutamente desnuda, tal no habría. O, más precisamente, solo habría historia sin más, historia a secas, como obra del logos divino. "[L]a verdad misma (que es Dios)", escribe Arzans rememorando las fiestas potosinas de canonización de Ignacio de Loyola en $1624 .{ }^{2}$ Con lo cual, si la historia se ordena solo por la verdad misma, la verdad que es Dios, la verdad es que la historia sería solo la historia de Dios (doble genitivo: tanto la historia hecha por Dios como la historia acerca o sobre Dios). Por eso, para que haya historia, otra historia que simple teología o teohistoriografía, en tal caso incluso Dios - sugiere Arzans - tiene que echar mano a la poesía. La fórmula "la verdad misma (que es Dios)" viene, pues, en la siguiente descripción de las fiestas de canonización del fundador de los Jesuitas, donde las figuras de las sibilas operan como "templados órganos" poéticos para la voz divina:

"De aquí se continuaba la adornada calle hasta la plazuela del Rayo, adonde estaba un hermoso teatro cubierto [...] de ricas telas, y en 12 ricas sillas estaban las 12 sibilas [y aquí nombra a cada una], todas con riqueza y distinción de traje; [...] todo causaba alegría y admiración pues (como templados órganos para la poesía) la misma verdad (que es Dios) profetizó cosas milagrosas por ellas" [...]. (Arzans, 1965: 16).

Incluso Dios, entonces, si ha de hacer historia que no sea mera teología, tiene que valerse de esos "templados órganos para la poesía" que son aquí las sibilas.

Dejemos por ahora reposar estas quijotescas locuras potosinas.

La figura del "poeta historiador" o "historiador poeta" (en ocasiones llamado simplemente "poeta") Juan Sobrino, quien habría escrito una historia de Potosí en versos octosílabos, dejada inconclusa a su muerte en $1649,{ }^{3}$ y que Arzans usa abundantemente como fuente para los siglos XVI y XVII pero que raramente cita, ilustraría a las claras la "vestidura" de la

\footnotetext{
2 Arzans fecha estas fiestas en 1624, aunque Ignacio de Loyola fue canonizado por Gregorio xv en 1622. ¿Imprecisión de Arzans o demora en los festejos potosinos? Probablemente lo primero, pues para la beatificación (reconocimiento de calidad de beato) de I. de Loyola, en 1608, ese mismo año se realizaron fiestas en Lima, Cuzco y, probablemente, Potosí (adonde los jesuitas habían llegado alrededor de 1575), pero que Arzans sorprendentemente omite.

3 Y que, como que en el caso Arzans, según su Historia, habría sido continuada en parte por su hijo.
} 
verdad desnuda por la poesía. Refiriéndose a una trifulca en Potosí entre vicuñas y vascongados en 1588, Arzans se explica:

"Lo particular de esta batalla [entre vicuñas y vascongados], destreza en sus encuentros, suerte y contrario que le ocupó a cada uno, lo escriben largamente el capitán Pedro Méndez, don Antonio de Acosta [otros historiadores tempranos de Potosí de los que se sirve Arzans] y el insigne Juan Sobrino, el cual lo escribió en verso y bien diferente de los otros historiadores, pues él como poeta pudo y quiso contar o cantar la cosa no como fue sino como debía ser, y los historiadores Méndez y Acosta la escribieron no como debía ser sino como fue, sin añadir ni quitar a la verdad cosa alguna. Y esto no es cosa nueva, que a fe que no fue tan piadoso Eneas como Virgilio lo pinta, ni tan prudente Ulises como lo escribe Homero" (Arzans, 1965: 18; subrayo).

Esta última referencia a Virgilio y Homero en la caracterización de sus personajes, permite entender mejor el "como debía ser" de la historia atribuida al poeta Sobrino. No se trataría de un "deber ser" moral a establecer para contar o cantar la historia sino, según lo piensa Aristóteles en su Poética, como una historia de tipos humanos (el piadoso Eneas, el prudente Ulises) o sucesos modélicos, más generales que el particularismo histórico (eso hace que Aristóteles argumente que la poesía sea más filosófica -léase: más general, más conceptualizable-que la historia). ${ }^{4}$ Es decir, el poeta que crea o viste los sucesos de la historia que cuenta podría decirse que es a la vez un tipógrafo. Aristóteles: "Es general [en poesía] a qué tipo de hombres les ocurre decir tales o cuales cosas verosímil o necesariamente, que es a lo que tiende la poesía" (Aristóteles, 2010; subrayo].

¿De dónde saca todas estas ideas Arzans? ¿Está leyendo a Aristóteles? La Poética no aparece en las fuentes de la Historia de Arzans enumeradas por esos dos tremendos eruditos que fueran Lewis Hanke y Gunnar Mendoza, coeditores modernos de la Historia. Además Aristóteles jamás dice que la diferencia entre historiador y poeta está en que el primero tiene que contar la historia como fue y el segundo como debía ser; lo que le corresponde al poeta, según la Poética, es contar lo que podría suceder, lo posible, y no lo que debió o debería ser, como apunta Arzans. En verdad, Arzans está haciendo aquí copy paste de otro libro no consignado por Hanke y Mendoza entre las fuentes de la Historia. Me refiero a El ingenioso Hidalgo

4 Aristóteles, 2010: 158: “[L]a poesía es más filosófica y elevada que la historia; pues la poesía dice más bien lo general, y la historia lo particular. Es general a qué tipo de hombres les ocurre decir tales o cuales cosas verosímil [eikos] o necesariamente, que es a lo que tiende la poesía". 
Don Quijote de la Mancha. ${ }^{5}$ Escribe Cervantes (Cide Hamete Benegeli o quien fuera), en el tercer capítulo de la segunda parte de El Quijote:

“- Ahí entra la verdad de la historia - dijo Sancho.

- También pudieran callarla por equidad - dijo don Quijote, pues las acciones que ni mudan ni alteran la verdad de la historia no hay para qué escribirlas, si han de redundar en menosprecio del señor de la historia. A fee que no fue tan piadoso Eneas como Virgilio lo pinta, ni tan prudente Ulises como lo describe Homero.

-Así es -replicó [el bachiller] Sansón [Carrasco]-; pero uno es escribir como poeta y otro como historiador: el poeta puede contar o cantar las cosas, no como fueron, sino como debían ser; y el historiador las ha de escribir, no como debían ser, sino como fueron, sin añadir ni quitar a la verdad cosa ninguna." (Cervantes, 1994; Subrayo).

Y en cuanto a la frase "la misma verdad (que es Dios)", Cervantes pone en boca del Quijote algo no muy diferente algunas líneas más adelante:

-A escribir de otra suerte - dijo don Quijote-, no fuera escribir verdades, sino mentiras; y los historiadores que de mentiras se valen habían de ser quemados, como los que hacen moneda falsa [...] La historia es cosa sagrada; porque ha de ser verdadera, y donde está la verdad, está Dios, en cuanto a verdad [...]" (Cervantes, 1994: 3].

El discurso de Cervantes puesto en boca del Quijote anuncia la ironía moderna, tan cara al romanticismo, aunque no - aparentemente- el discurso que Arzans se atribuye a sí mismo. Pero dado que este está citando ahí sin citar, sin marcar la cita como tal, ¿quién podrá algún día decidir sobre el estatus (irónico o no, por ejemplo) de su frase?, ¿quién podrá algún día probar, lo que se llama probar, que Arzans no habrá estado ahí, y en otros pasajes de su Historia, forjando una verdadera falsa moneda? ¿Simple literatura? (Como la misma Historia de la Villa Imperial de Potosí lo muestra a cada paso, la historia de Potosí habrá estado llena de historias de falsas monedas, siendo ello un permanente dolor de cabeza para las

\footnotetext{
5 Aunque ni Hanke ni Mendoza identificaron a El Quijote como fuente de la Historia (ninguna obra de Cervantes está incluida por demás en el índice de los libros citados explícita o implícitamente por Arzans; cf. "Bibliografía", in tomo III, pp. 505-523), el primero es enfático en señalar a Cervantes como una de las fuentes literarias más importantes de la misma: "La prosa literaria de Arzans está claramente influida por Cervantes" [...] "Cervantes, a quien Arzans no cita." (Hanke, 1965: XCviII).
} 
autoridades de la monarquía española en tales parajes, comenzando por las de la Casa de Moneda).

En cualquier caso, en cuanto al "poeta historiador" Juan Sobrino, pero también en cuanto a esos historiadores tempranos de la Historia, compelidos a contar como las cosas fueron, sin añadir ni quitar a la verdad cosa alguna (el capitán Pedro Méndez, el portugués Antonio de Acosta, y los criollos Juan Pasquier y Bartolomé Dueñas), ellos son, para Mendoza y Hanke fuentes historiográficas altamente "problemáticas", pues, hasta hoy, de ellos no se ha hallado prueba bibliográfica ni biográfica alguna. ${ }^{6}$ Mendoza se pregunta si tales historiadores no serían parte de una ficción historiográfica (sino histórica) del propio Arzans, suerte de heterónimos pessoanos avant la lettre. Pero de lo que Mendoza no duda es que en no pocos pasajes de la Historia (particularmente aquellos más alejados en el tiempo de su escritura, y que, por tanto, no podían ser controlados por sus contemporáneos), el discurso histórico se ficcionaliza y, en otros, la ficción se historiza. A ello le llama "técnica de superposición", particularmente en la elaboración de "los materiales no rigurosamente históricos" (historias de aparecidos, milagros, amores y otros). Para Mendoza no se trataría de un problema de verosimilitud sino llanamente de realidad e irrealidad: "A veces sobre los elementos reales se superponen elementos irreales... [para hacer más ameno el relato]. Otra veces se superponen elementos reales sobre elementos irreales... para crear una sensación artificial de realidad" (Arzans, 1965: XCII).

Si en algunos casos es posible zanjar fácilmente lo supuestamente real de lo irreal, porque existen otros documentos (externos a la Historia de Arzans), que permiten tal delimitación, ¿cómo zanjar cuando tales documentos no existen? "Las preguntas sobre la veracidad de Arzans no cesarán, antes bien es posible que aumenten en el curso de los años", auguraba ya en 1965 Lewis Hanke (1965: Lxxxix). Ahora bien, todo esto se complica un poco, porque el criterio de veracidad (es decir, de decir verdad) para juzgar una historia parece insuficiente, o al menos problemático, cuando esa misma historia afirma que la verdad misma, la verdad desnuda, es obra

6 Con excepción de Juan Sobrino; Hanke y Mendoza remiten a documentos de la primera mitad del siglo xvir en que aparece citado un alférez Juan Sobrino, del bando de los vicuñas, pero no hay claridad si este es el mismo "poeta historiador" que es mencionado en la Historia (Arzans, 1965: LIV); de su historia escrita en versos (como de otras tres historias potosinas en verso que menciona Arzans en su Historia) tampoco se ha hallado rastro documental alguno. 
divina y, por ello, no hay historia humana expurgada de poesía. Y aunque Mendoza rechaza plantear el problema en términos de verosimilitud ${ }^{7}$ (uno de los criterios por excelencia para evaluar las obras poéticas, según Aristóteles), tal vez en este punto el coeditor de la Historia se apresura. Ante un discurso (histórico) que no es factible evaluar o zanjar en términos de verdad, la atención a su verosimilitud no puede descartarse. Es el ejercicio que nos proponemos hacer a continuación con respecto al pasaje de la Historia relativo a la escenificación en 1555 en Potosí de una versión temprana, "en verso mixto del idioma castellano con el indiano", de las escenificaciones altoperuanas de la captura y muerte de Atahualpa.

Sin demorarnos ahora en la noción de verosimilitud, subrayemos, con todo, que esta no es simple. Aristóteles llega a decir que una fábula puede ser incluso imposible, y, sin embargo, verosímil. La verosimilitud, la de la poética como de la retórica clásica al menos, tiene principalmente que ver con las orientaciones y/o creencias culturales vigentes o aceptadas. La verosimilitud de la intervención de demonios o de dioses en la historia, por ejemplo, tendría más que ver con el marco cultural vigente en un momento dado que con su facticidad o aun posibilidad intrínseca (si tal existiera) de la misma ( $c f r$. Brunschwig y Lloyd, 2000). Por demás, la verosimilitud de la historia misma, la historia a secas (una y única), pudiera revelarse al fin y al cabo también como un acontecimiento datado.

III

Arzans describe latamente unas "solemnísimas fiestas que celebraron [en Potosí] así los españoles como los indios" en 1555, con motivo de la aclamación "por sus primeros patronos a Cristo nuestro señor sacramentado, a la santísima Virgen en su purísima concepción y al apóstol Santiago" (Arzans, 1965: 1-2). Estas fiestas, que comprendieron procesiones religiosas y profanas, arcos triunfales, comedias, paseos, saraos y juegos varios, duraron quince días en sus aspectos solemnes y religiosos, más una semana adicional en sus elementos festivos y profanos. Para el relato de los primeros quince días Arzans se acredita en las historias de Antonio

7 Mendoza: "El problema no es, pues, como se insistirá posteriormente, de verosimilitud o inverosimilitud, sino de realidad e irrealidad" (nota 3, Ia, VI, 5); y, sin embargo, en otra parte habrá reconocido que la cosa es menos simple: "El problema de la realidad y la irrealidad en Arzans no es, pues, tan simple” (Arzans, 1965: CXII). 
Acosta y de Juan Pasquier; para la semana adicional, de las historias del capitán Pedro Méndez y de Bartolomé Dueñas.

En la semana de "regocijos varios", Arzans cuenta que se representaron ocho "comedias": cuatro representadas por "nobles incas". De las comedias de españoles Arzans no dice nada. En cambio, las cuatro comedias interpretadas por nobles indígenas, en "verso mixto del idioma castellano con el indiano", las describe ampliamente. En ellas se representaron: 1. "El origen de los monarcas ingas del Perú", con el "felicísimo Mancco Ccápac"; 2. "Los triunfos de Huayna Ccápac"; 3. "Las tragedias de Cusi Huáscar, 12a inga del Perú"; y, 4. "La ruina del imperio inga". Esta última es descrita en los siguientes términos:

Representóse en ella la entrada de los españoles al Perú; prisión injusta que hicieron de Atahuallpa, $13^{\circ}$ inga de esta monarquía; los presagios y admirables señales en el cielo y aire que se vieron antes que le quitasen la vida; tiranías y lástimas que ejecutaron los españoles con los indios; la máquina de oro y plata que ofreció porque no le quitasen la vida, y muerte que le dieron en Cajamarca (Arzans, 1965: 2).

Tras referirse a las comedias de los "nobles indios", Arzans describe también un vistoso "paseo" en que desfilaron "todas las naciones de indios que habitan esta América Meridional del Perú", tras los cuales "se seguían por su orden todos los ingas del Perú, desde el famoso Mancco Ccápac hasta el valeroso Sayri Túpac, que en aquella sazón [1555] vivía y molestaba a los españoles vecinos del Cuzco y de Huamanga con sangrientas guerras"; aunque, agrega Arzans, "quien más se señalaba entre los ingas de este paseo era el soberbio Atahuallpa (que hasta en estos tiempos [es decir, comienzos del siglo XVIII] es tenido en mucho de los indios, como lo demuestran cuando ven su retrato)".

Cabe recordar que en el curso de su Historia Arzans alude a otra "comedia" relativa a la historia de los incas. Se trata de la obra titulada "Prosperidad y ruina de los incas del Perú", cuyo autor habría sido precisamente el poeta Juan Sobrino, y que se habría representado en Potosí en 1641, junto a otras tres comedias (de las cuales nuevamente Arzans no nos dice nada), con ocasión de una vistosas bodas que pusieron momentáneo fin a las disputas entre vicuñas y vascongados. Arzans la describe en detalle. Me limito a citar aquí un esquema mínimo: "Representóse en ella su origen [de los incas]... Representóse también la entrada y descubrimiento del Perú por el marqués Francisco Pizarrro y el motivo de las guerras 
civiles... Representóse asimismo la grande riqueza que tuvieron aquellos reyes [incas], trágica muerte de Huáscar inga y el bastardo Atahuallpa, y últimamente la ruina y acabamiento de estos monarcas con la venida del Virrey don Francisco de Toledo" [y la muerte del último inca de Vilcabamba, Túpac Amaru] (Arzans, 1965: 20).

IV

Limitándonos por ahora a las "comedias" de 1555, hasta fines del siglo pasado todos los autores que se refirieron a ellas - ya en el contexto de estudios sobre la Historia de Arzans, ya en el marco de estudios sobre el ciclo dramático altoperuano de la captura y muerte de Atahualpa- no cuestionaron la veracidad ni la verosimilitud del relato de Arzans. ${ }^{8}$ Pero en 1986 y 1988 los historiadores peruanos Alberto Flores Galindo y Manuel Burga plantearon que no resultaba verosímil que tales comedias se hubieran representado "tan temprano", en 1555; el primero, a diferencia del segundo, sin aportar mayores argumentos. ${ }^{9}$ Desde entonces ha habido quienes han aceptado los argumentos adelantados por Burga, aunque sin aportar nuevas consideraciones. ${ }^{10} \mathrm{Ha}$ habido también quienes han intentado refutarlos, manteniendo la acreditación acerca de la veracidad del texto de Arzans, aunque, a nuestro juicio, con planteamientos poco convincentes. ${ }^{11} \mathrm{Y}$ ha habido por último quienes no se han dado por enterados de los cuestionamientos y han seguido acreditando sin más el relato de Arzans. ${ }^{12}$

Los argumentos de Burga, en Nacimiento de una utopía: muerte y resurrección de los incas (1988), habrán sido básicamente tres:

8 Por ejemplo: Lara 1957; Mesa y Gisbert 1965, Gisbert 1968; Wachtel 1971, Cid 1973; Bedrow 1987.

9 Flores Galindo sostuvo lacónicamente: "Según el cronista Arzáns y Vela, la primera representación de la muerte del inca habría tenido lugar en Potosí en 1555. Pero Arzans escribió en 1705. No parece verosímil que desde una fecha tan temprana [...] pudiera exaltarse a los incas en una población española, cuando todavía el recuerdo del pasado andino no había sido reconstruido en la memoria colectiva"; A. Flores Galindo, 1994: 49. Cfr. refutación (infundada a nuestro juicio) en Ares Queija, 1992.

10 Por ejemplo: García Pavón 1992; Cornejo Polar 1993; Perissat 2000; García Bedoya 2008.

11 Por ejemplo: Husson 1998; Varón 1998.

12 Por ejemplo: Giletti Benso 1995; Beyersdorff 1997; Gisbert 2001. 
1. No le parece factible "tanto lujo, magnificencia y ostentación de españoles e indígenas a [apenas] diez años de la fundación” de Potosí.

2. No le parece plausible "celebrar públicamente a los incas, recordarlos en mascaradas, incluso a Sayri Túpac, cuando aún oponían una tenaz resistencia a la dominación española desde Vilcabamba”.

3. Le parece inverosímil que se celebrase en aquella fecha, "con lágrimas y lamentos, la caída de un imperio, y de Atahuallpa en particular" cuando, "como lo recuerda insistentemente Garcilaso, una nutrida tradición oral de burla y desprecio por este inca era muy popular en el sur [del virreinato]" (Burga, 1988: 408-412).

Finalmente, la duda sobre la existencia de las fuentes citadas por Arzans (Méndez y Dueñas, Acosta y Pasquier), planteadas ya por Mendoza, así como la nula referencia a algo parecido en Potosí o en otras ciudades del virreinato peruano por parte de otros historiadores conocidos, terminan por precipitar su convicción:

Definitivamente pienso - concluye Burga - que esta fiesta ha debido transcurrir, pero a fines del siglo XVII o a inicios del xviII, cuando el autor pudo verla directamente y aun hacer sus primeros borradores en el transcurso de la fiesta. En todo caso, esto queda también como un tema aún no totalmente resuelto (Burga, 1988: 412).

La última frase no deja de ser interesante: "En todo caso, esto [es decir, si Arzans vio tales representaciones en vida, y las retro-proyectó en el tiempo] queda... como un tema aún no totalmente resuelto" (volveremos sobre esto).

V

A continuación ofrecemos otros tres argumentos para considerar inverosímil la historia de la representación de comedias de incas en 1555 en Potosí que nos cuenta Arzans. Luego, para finalizar, abordaremos la cuestión de si tales comedias se dieron alguna vez en el Potosí colonial, es decir, si el relato de Arzans es aquí "vestidura" (ampliación, exageración) o llana "creación" de un suceso.

Un primer argumento es de orden lingüístico. Recordemos que según Arzans las cuatro comedias interpretadas por "nobles indios” en 1555 eran 
en "verso mixto del idioma castellano con el indiano". ¿Cuál es el "idioma indiano" al que se refiere Arzans? Cada vez que menciona el idioma "indiano" en el curso de su Historia, Arzans lo hace en referencia al quechua ( $\mathrm{I}^{\mathrm{o}}, \mathrm{IV}, 2 ; \mathrm{I}^{\mathrm{o}}, \mathrm{V}, 5 ; \mathrm{I}^{\mathrm{a}}$, VI, 19 , etc.); Hanke y Mendoza concuerdan en este punto. ${ }^{13}$ Por si quedaran dudas: unas páginas antes de la escena de las comedias de 1555, en un pasaje que remite a 1553, Arzans cita el grito de "los indios" de Potosí ante la aparición de unas señales en el cielo, y la frase está en quechua; lo mismo ocurre en tal ocasión con el fraseo del indio "sabio" Puma Soncco, que Arzans también cita tanto en quechua como en castellano ( $\left.\mathrm{I}^{\mathrm{a}}, \mathrm{III}, 7 ; 1965\right)$. Actualmente las zonas rurales de Potosí son básicamente (bilingües) quechua-hablantes. ¿Pero en 1555? Los lingüistas afirman que entonces era una región básicamente aymara-hablante (Torero, 1987); los indios mitayos de los primeros años venían de los alrededores del por entonces "asiento minero" (se convertiría en "villa" recién en 1563); solo más tarde, con la nueva tasa del Virrey Toledo (1573), llegarían contingentes de mitayos provenientes de zonas quechua-hablantes, incluso del sur del Cuzco (canas y canchis, entre otros), que transformarían drásticamente el paisaje lingüístico potosino. No resulta verosímil la puesta en escena de comedias bilingües en castellano y quechua en Potosí, en 1555, si (salvo quizás unos cuantos yanaconas) ni los indios que laboraban el Cerro Rico podrían haberlas entendido. ${ }^{14}$

Un segundo argumento tiene que ver con las discrepancias entre lo que Arzans dice con respecto a lo ocurrido en Potosí el año 1555 en la

13 Cfr. Arzans, 1965: 17, y su cotejo con la entrada quechua en el índice preparado por Gunnar Mendoza (Arzans, 1965: 549).

14 Husson, reconociendo esta dificultad, plantea la hipótesis de que los "indios nobles" que montaron las comedias en 1555 eran parte de una "embajada" del reino neoinca de Vilcabamba (Husson 1998). Pero, aparte de minimizar la cuestión lingüística y de no explicar por qué la "embajada" de Vilcabamba se dirigió un "asiento minero" que carecía entonces de autoridades propias (sus corregidores fueron nombrados por la ciudad de La Plata hasta 1563), debiendo además desplazarse larguísimas distancias, olvida que Atahualpa era entonces odiado por los incas de Vilcabamba, como lo recuerda Burga, recordando a Garcilaso. Ni en los desfiles de "reyes incas" realizados en Cuzco y Lima bien entrado el sigo XVII Atahualpa formaba parte de los monarcas representados. Que Atahualpa no era especialmente querido en Vilcabamba, lo muestra la siguiente historia: "Cuando en 1557 salió de las montañas el inca Sayrí Tupac [sic] y fue traído a Lima, al pasar por Guamanga, Astete le obsequió la borla colorada que conservaba en poder desde que la quitó a Atahualpa en Cajamarca. Sayrí manifestó contento, pero fue fingido como se supo después; siendo evidente que no podía mirar con aprecio una prenda de Atahualpa, el destructor de su familia" (Mendiburu, 1880, Lima; subrayo). 
Historia y en los Anales. En sus Anales de Potosí, obra que llega hasta 1702 (publicada en París en 1872), ${ }^{15}$ que, como su nombre lo indica, da cuenta de los principales sucesos ocurridos en Potosí año por año, constituyendo una especie de anticipo de su Historia, para 1555 no hay mención de fiesta alguna y mucho menos de comedias bilingües de la historia del incario. Da la impresión que para ese año Arzans no tenía nada que historiar, porque no alude a ningún hecho preciso en los Anales. Se limita a apuntar que "crecía en gran manera la población" y a comentar in extenso el influjo de los astros sobre el carácter de los potosinos: "dejándose llevar los moradores del influjo de las estrellas que predominan en Potosí, las cuales son Júpiter y Mercurio: este inclina a que sean sabios, prudentes e inteligentes en sus tratos y comercio; y, por Júpiter, magnánimos y de ánimos sumamente liberales", etc. Al escribir los Anales, Arzans ya contaba con los supuestos materiales de las fuentes problemáticas que le sirven para describir las fiestas de 1555 en la Historia, pues en los Anales los menciona. En la Historia todas las disquisiciones sobre los influjos astrales desaparecen en 1555, y ese año solo se ocupa de las fiestas de marras. Que entre el año del término de los Anales (1702) y cuando escribe los capítulos de las fiestas de 1555 de la Historia (1705), Arzans hubiera de pronto encontrado entre los papeles de Méndez, Acosta, Pasquier y Dueñas detalladas descripciones de las susodichas fiestas, resulta inverosímil. Es más verosímil imaginar que, a falta de datos históricos "duros" para el año 1555 (como es evidente en los Anales), Arzans echó mano a sus heterónimos historiadores para contar una historia "de relleno", no solo entretenida sino también, hasta cierto punto, ejemplar... Por demás, en los Anales no hay mención alguna de alguna procesión, desfile, mojiganga, máscara o comedia de incas o indios de cualquier tipo durante el siglo Xvi.

Un tercer argumento para cuestionar la verosimilitud de Arzans en este punto nos lo proporciona él mismo. Una especie de guiño al discreto lector ("Prologo", I' ${ }^{\mathrm{a}}$ ). Por una parte, Arzans nos dice que para describir las comedias interpretadas por los nobles indios se basó en los materiales de los historiadores Pedro Méndez y Bartolomé Dueñas, pero, acto seguido disiente con ellos en un punto crucial: el carácter de tales puestas en escena. Dice Arzans, justo después de describir las cuatro mentadas comedias: "Fueron estas comedias (a quienes el capitán Pedro Méndez y

15 In Archivo Boliviano, Vicente de Ballivian y Roxas editor, tomo I ${ }^{\circ}$, París, A. Franck (F. Vieweg), 1872. 
Bartolomé Dueñas les den el título de sólo representaciones) muy especiales y famosas..." (Arzans, 1965: 2).

Si sus alegadas fuentes consideraban que no eran propiamente comedias sino "sólo representaciones", ¿cómo Arzans podía afirmar algo diferente, dado que en ese capítulo solo apela como fuentes a Méndez y Dueñas, las mismas fuentes que contradice? En cualquier caso cabe intentar aclarar primero el punto en litigio: "comedias" (Arzans) versus "sólo representaciones (Méndez y Dueñas). Seguramente nunca sabremos qué entendían Méndez y Dueñas (si alguna vez existieron) por "sólo representaciones", pero Arzans y otras fuentes coloniales que se refieren a las fiestas reales en el virreinato peruano nos dan algunas pistas. En ellas eran habituales tanto "mojigangas", como "máscaras" y "comedias". Las primeras eran desfiles cómicos, de personajes portando atavíos y máscaras de animales, figuras mitológicas u otras, $y$, en general, no eran consideradas representaciones, como sí, a veces, las máscaras y, siempre, las comedias. Las máscaras eran, en general, más solemnes o serias que las mojigangas, y en ocasiones representaban cuadros o escenas vivientes, pero sin diálogo o apenas precedidos por unas loas sacras o profanas; y por ello a menudo las máscaras eran llamadas representaciones o, como dirían Méndez y Dueñas, "sólo representaciones" ( sin diálogo). De estas máscaras con cuadros vivientes, aunque sin diálogos, y con participación de figuras de monarcas incas, hay varias documentadas durante el siglo XVII y XVIII tanto en Lima, Cuzco como Quito, y en más de una ocasión suscitaron trifulcas (Cfr. Espinoza, 2002).

VI

Para ir concluyendo: ¿tales comedias se dieron alguna vez en el Potosí colonial? ¿La historia de Arzans es aquí poética "vestidura" (ampliación, exageración de hechos "reales") o nomás "creación" de los mentados "sucesos"? ¿Las vio Arzans, a fines del siglo xVII o comienzos del XVIII, como imagina Burga, y luego las retro-proyectó a los albores de la Villa Imperial? En este punto, nos apartamos de lo que imagina el historiador peruano. Es más verosímil que Arzans jamás las presenciara, aunque es muy probable que escuchara hablar de ellas. Veamos. 
A comienzos del siglo XVIII, en los mismos años en que Arzans escribía su Historia, el viajero francés Amédée-François Frézier, estando en Lima en 1713, anota en su diario de viajes por las costas de Perú y Chile:

“[S]e honra todavía [...] la memoria de la soberanía de ese emperador a quien se despojó injustamente de sus estados, y de la muerte de Atahualpa, a quien, como se sabe, Francisco Pizarro hizo degollar cruelmente [como se ve, aun un ilustrado francés compartía la memoria traspuesta del "degollamiento" del Inca, al igual que Guaman Poma y el propio Arzans]. Los indios no lo han olvidado [...] En la mayoría de las grandes ciudades de tierra adentro [avancées dans la terre] celebran la memoria de esta muerte con una especie de tragedia que representan en las calles [une espèce de Tragedie qu'ils font dans la rue], el día de la Natividad de la Virgen. Se visten a la antigua y llevan aun las imágenes del sol, su divinidad, de la luna y demás símbolos de su idolatría, como bonetes en forma de águila o de cóndor, o vestidos de plumas y alas tan bien dispuestas que desde lejos semejan pájaros. Esos días beben mucho y tienen en cierto modo toda clase de libertades. [...] Se trata siempre de suprimir esas fiestas [On tâche tous les jours de supprimer ces fêtes] y desde hace algunos años se les ha suprimido el teatro donde representaban la muerte del Inca." (Frézier, 1982: 233-34). ${ }^{16}$

Si le damos crédito a Frézier - y cómo no dárselo, aunque él haya oído referir esto en Lima, Pisco o Ilo, sin haberlo presenciado directamente-, ¿cuáles habrán sido esas "grandes ciudades de tierra adentro" o "del interior" en que los indios representaban esa "especie de tragedia" de la muerte de Atahualpa? Probablemente no el Cuzco, pues sino dispondríamos casi con toda seguridad de fuentes documentales al respecto (y no es el

16 Hay una incongruencia en el relato de Frézier, que mencionamos al paso. Primero nos dice que tales representaciones indígenas se realizaban en la calle y luego que desde hace algunos años "se les ha suprimido el teatro" [subrayo] donde las representaban. Por lo anterior, queda abierta la cuestión de si tal tipo de escenificación se realizaba en la calle o en un teatro (o en ambos tipos de lugares), así como si se representaban en una o "en la mayor parte" [la plupart] de las ciudades del interior. Otrosí: en vistas de que Frézier señala que estas representaciones se hacían "el día de la Natividad de la Virgen", el 8 de septiembre, cabe indagar la posible vinculación de tal indicación con las fiestas de la Virgen de Cocharcas (en el actual departamento de Apurímac), cuya devoción, una de las más importantes del Perú, remonta a fines del siglo xvi, y donde hasta hoy se bailan en su honor, todos los 8 de septiembre, pasos "incas" relativos a la muerte de Atahualpa. La devoción mariana de Cocharcas está vinculada históricamente con la devoción de Copacabana, junto al Titicaca, pues desde ahí fue traída su imagen (una réplica de la de Copacabana) a fines del siglo Xvi por Sebastián Quimichi (hijo de un curaca de Cocharcas), quien, al llegar al Callao tuvo un sueño premonitorio y terapéutico por parte de la Virgen, viajó a Potosí en busca de limosnas, regresó a Cocharcas con la imagen mariana y, falleció más tarde en Cochabamba. 
caso). Probablemente tampoco Potosí, pues en caso contrario el mismo Arzans o su hijo Diego habría(n) dejado testimonio fidedigno de ellas. Tal vez Huamanga, Huánuco o Jauja, en la sierra central peruana, y/o más al norte, en Cajamarca, donde otro ilustrado temprano, el obispo Martínez Compañón, mandó literalmente a ilustrar una representación de los sueños premonitorios de Atahualpa y de la muerte de este a manos de Pizarro, en las postrimerías del siglo XVIII (Cfr. Martínez, 1978).

En cualquier caso, si en 1713 Frézier escuchó esta historia de escenificaciones de la muerte de Atahualpa en la costa peruana, con toda seguridad Arzans habrá oído hablar de ellas en Potosí. ¿Pero por qué decimos que no las vio, que jamás asistió a una escenificación indígena de la captura y muerte de Atahualpa? Por dos razones. Primera: La descripción de la comedia de "la ruina del imperio inga" que hace Arzans, aunque refiere a Atahualpa, no tiene nada que ver con la trama del ciclo dramático altoperuano como se conoce en Bolivia, al menos desde fines del siglo xix, y en el norte del Perú desde fines del XviII. En Arzans no hay ninguna alusión al sueño premonitorio del Inca, ni tampoco al layqa o willaq umu Waylla Wisa, personaje central del drama, ni a las ñustas o pallas, ni a la "maldición del Inca", etc., etc..

Segunda razón, complementaria: cuando Arzans se refiere al contenido de los dramas incaicos (incluyendo aquel que le atribuyo al poeta Sobrino), no está describiendo un drama; no hay escenas, ni hay acción ni diálogos. Arzans está simplemente aludiendo a una historia, la historia inca, y, en lo esencial, está siguiendo al Inca Garcilaso (y al Palatino citado por Garcilaso). ¡Incluso se refiere a Atahualpa como "el bastardo Atahualpa"!, siguiendo otra vez a Garcilaso, lo cual no tiene ninguna relación, reiteramos, con las distintas variantes tanto peruanas como bolivianas del ciclo dramático de Atahualpa.

En cualquier caso, Arzans era poco afecto a recordar las fábulas o tramas de las comedias, incluso las que debió haber visto en Potosí, pues las nombra, a comienzos del siglo xviII. En su Historia, menciona alrededor de setenta comedias que se habrían dado en Potosí entre mediados del siglo XVI y comienzos del XviII; unas pocas, con título (como algunas de Calderón y de Moreto, e incluso "Los españoles en Chile", de Francisco González Bustos, en 1735, es decir, estando él casi con toda seguridad de cuerpo presente en la representación que le ofrecieron clérigos al arzobispo de La Plata, Alfonso del Pozo y Silva, en "las casas" del "comisario de la santa Inquisición” [ cfr. Arzans, 1965: 16]). Pero de ninguna de ellas, de las 
casi setenta comedias aludidas, describe su trama ni menciona caracteres o personajes, salvo de las comedias o "sólo representaciones" interpretadas por "nobles indios" de 1555 y de "Prosperidad y ruina de los ingas del Perú", que atribuye a Juan Sobrino. Tramas que no son tramas (no dramáticas tramas), reiteramos. Sino, en ambos casos: la historia contada por el Inca Garcilaso.

\section{$* * *$}

En síntesis sin sín-tesis, ¿cría (crea) Arzans, en este caso, o viste la "verdad desnuda” que tanto él como Alonso Quijano alias don Quijote (II, 2 y 3 ) asignan como telos a la historia? Como su acaso heterónimo poeta historiador Sobrino, el Arzans poeta historiador de las fiestas de 1555 jamás habrá creado los "sucesos" ex nihilo; los habrá vestido, si se quiere, multiplicando las instancias de investidura (Acosta, Méndez, Pasquier, Dueñas, etc.). Tal ficción tan histórica como historiográfica: tal "falsa moneda" en curso antes y después de la estructuración de la oposición inversamente jerárquica entre "verdad" y "ficción", "historia” y "poesía” (Derrida 1991). ${ }^{17}$ En cuanto a Cervantes, son conocidas sus "vale un Potosí" así como, tras su cautiverio en Argel, su solicitud a Felipe in en mayo de 1590 para obtener un corregimiento vacante en Charcas ("de los tres o cuatro que al presente están vacíos" en las Indias) (Cfr. Taboada, 2005: 10-11; Arellano y Ecichmann, 1999).

17 Derrida: "la historia [de la "La falsa moneda" en los Spleen de Paris de Baudelaire] es — tal vez [peut être] -, como literatura, falsa moneda, una ficción [...] A menos que esta oposición entre verdadera y falsa moneda pierda aquí su pertinencia - y tal sería una de las demostraciones de esta experiencia literaria, de este lenguaje como falsa moneda [fausse monnaie] cada vez posible." (Derrida, 1997: 113, 197 y 199; trad. del suscrito). Una acuñación no acreditada por el poder institucional puede llegar a circular como moneda acreditada sin jamás ser denunciada; ello abre la posibilidad de una indecidibilidad constitutiva de la acuñación sin ley, donde, como subraya Derrida, la oposición entre verdadera y falsa acuñación pierde pertinencia. Ello, sin reiterar que una acuñación puede ser acreditada como verdadera sin serlo por segmentos específicos de la institución, como a menudo ocurriera en la Casa de Moneda de Potosí. Cf. "Memorial, que en 7. de Nouiembre de 1650 dio al Rey nuestro Señor (que Dios guarde) el Doctor Consultor del Santo Oficio, Tesorero, y Procurador General de la Cathedral de Arequipa, en razon de la moneda falsa que de algunos años a esta parte se ha labrado en la Villa de Potosi, y de los muchos derechos de quintos, y aberias que se usurpan, y del remedio de todo, sin daño de ningun vassallo, $y$ con aprouechamiento de la Real hazienda, en mayor cantidad de doze millones de oro y plata en cada un año. Don Alonso Merlo de la Fuente" (Giráldez, 2006). 


\section{BiBLIOGRAFÍA}

ARES QUEIJA, B. (1992); "Representaciones dramáticas de la conquista: el pasado al servicio del presente", en Revista de Indias (Madrid) 52, 195-196, mayo-diciembre, pp. [231]-250.

ARISTÓTELES (2010); Poética, trad. V. García Yebra. Madrid: Gredos.

ARZANS, B. (1965 [s. XVIII]); Historia de la Villa Imperial de Potosí, edición a cargo de Gunnar Mendoza y Lewis Hanke. Providence: Brown University Press. (1872 [s. XVIII]); Anales, en Vicente de Ballivian y Roxas (ed.), Archivo Boliviano, t. I. París: A. Franck (F. Vieweg).

BEDROW, L. (1987); “La escena de la 'Muerte del Inca' ”, en Hipótesis. Revista boliviana de literatura. La Paz, pp. 319-329.

BEYERSDORFF, M. (1999 [1997]); Historia y drama ritual en los Andes bolivianos (siglos XVI-XX). La Paz: Plural.

BURGA, M. (1988); Nacimiento de una utopía: muerte y resurrección de los incas. Lima: Instituto Agrario.

BRUNSCHWIG, J., y G. Lloyd (2000); “Retórica”, en El saber griego. Madrid: Akal.

CERVANTES, M. de (1994 [1615]); El Quijote de la Mancha, 2a parte. Madrid: PML Ediciones.

CID, J. (1973); Teatro indoamericano colonial. Madrid: Aguilar.

CORNEJO POLAR, A. (1993); Escribir en el aire. Lima: Horizonte.

DERRIDA, J. (1991); Donner le Temps (1. La fausse monnaie). París: Galilée.

ESPINOSA, C. (2002); "El retorno del inca: los movimientos neoincas en el contexto de la intercultura barroca”, en Procesos. Revista Ecuatoriana de Historia, núm. 18, Quito.

FLORES GALINDO, A. (1994 [1986]); Buscando un inca, 4a ed. Lima: Horizonte.

GARCÍA BEDOYA, C. (2008); "Pasados imaginados: la Conquista del Perú en dos obras dramáticas coloniales”, en I. Arellano y J. A. Rodríguez (eds.), El teatro en la Hispanoamérica colonial. Madrid: Iberoamericana.

GARCÍA PAVÓN, L. (1992); “Comunicación, escritura e imaginario social en la Tragedia del fin de Atahuallpa”, en Caravelle, núm. 59, pp. 225-240.

GILETTI BENSO, S. (1995); "L'inca Atahualpa oltre la storia”, en Scrittura e riscrittura. Traduzioni, refundiciones, parodie e plagi. Roma: Bulzoni Editori.

GISBERT, T. (1968); Esquema de la literatura virreinal en Bolivia. La Paz: Facultad de Filosofía y Letras, Centro de Estudiantes. , (2001 [1999]); Paraíso de los pájaros parlantes (cap. "El control del imaginario. Teatralización de las fiestas”). La Paz: Plural. 
HANKE, L. (1965); "El valor literario de la Historia", en B. Arzans, Historia de la Villa Imperial de Potosí, edición a cargo de Gunnar Mendoza y Lewis Hanke. Providence, Brown University Press.

HUSSON, J-Ph. (1998); “En busca del foco de las representaciones de la muerte de Atawallpa: algunos argumentos a favor del estado neo-inca de Vilcabamba”, en Nuevos Comentarios núm. 6: 50-81.

, (2001); La mort d'Ataw Wallpa ou La fin de l'Empire des Incas: Tragédie Anonyme en Langue Quechua du Milieu du XVIe Siècle. Ginebra: Patiño.

LARA, J., (1993 [1957]); Tragedia del fin de Atawallpa / Ataw Wállpaj p’uchukakuyninpa wankan. Buenos Aires: El Sol.

MARTÍNEZ COMPAÑ́́N y B. J. Bujanda (1978 [1782-85]); La obra del Obispo Martínez Compañón sobre Trujillo del Perú en el siglo XVIII. Madrid: Ediciones Cultura Hispánica.

MENDIBURU, M. (1880); Diccionario histórico-biográfico del Perú, t. 1. Lima: Imprenta de J. Francisco Solís.

MERLO DE LA FUENTE, A. (2006 [1650]); Memorial, en A. Giráldez, "La primera globalización y un inquisidor en el Potosí de 1650: El Memorial de Don Alonso Merlo de la Fuente", en eHumanista, v. 7.

MESA, J., y T. Gisbert (1965); "Noticias de arte en la obra de Bartolomé Arzáns de Orsú y Vela”, en Arzáns, Historia, vol. III.

PERISSAT, K. (2000); “Los incas representados (Lima - siglo XVIII): ¿supervivencia o renacimiento?”, Revista de Indias, vol. LX, núm. 220.

TABOADA TERÁN, N. (2005); Miguel de Cervantes Saavedra. Corregidor Perpetuo de Nuestra Señora de La Paz. La Paz: Plural.

TORERO, A. (1987); "Lenguas y pueblos altiplánicos en torno al siglo XVI”, Revista andina, Cusco, 5, 2, $2^{\circ}$ trimestre.

VARÓN, B. A. (1998); “Una aproximación al teatro colonial indígena sobre la conquista: los casos de Tlaxcala, Quesaltenango y Potosí", en Reverte Bernal y Reyes Peña (eds.), II Congreso Iberoamericano de Teatro: América y el Teatro Español, vol. 2. Cádiz: U. de Cádiz.

WACHTEL, N. (1971); La Vision des Vaincus. Les Indiens du Pérou devant la Conquête Espagnole (1530-1570). París: Gallimard. 